\title{
FORTALEZAS E FRAGILIDADES DO SETOR PISCÍCOLA EM SANTARÉM E MOJUÍ DOS CAMPOS, PA -BRASIL
}

\author{
Gina Cynthia Carneiro do Valle'; David Gibbs McGrath²; Charles Hanry Faria Junior ${ }^{3}$. \\ 1 Universidade Federal do Oeste do Pará, Santarém, Pará, Brasil, gcynthiavalle@gmail.com \\ 2 Universidade Federal do Oeste do Pará, Santarém, Pará, Brasil, dgmcgrath52@gmail.com \\ 3 Universidade Federal do Oeste do Pará, Santarém, Pará, Brasil, charlesufopa@gmail.com
}

RESUMO: Este trabalho objetiva apresentar as fortalezas e fragilidades dos produtores e instituiç̧̃es que atuam no setor aquícola de Santarém e Mojuí dos Campos, PA Brasil. Assim como, caracterizar esses produtores aquícolas; apresentar os objetivos e missão das instituições que atuam no setor aquícola; e quali-quantificar as fortalezas e fragilidades dos produtores e instituiç̃es locais. Realizou-se entrevistas qualitativas com aplicação de formulários e de roteiros semiestruturados, junto a 44 piscicultores e 08 representantes das associações, cooperativas, agências de fomento e órgãos responsáveis pela atividade aquícola. Também foram realizados registros fotográficos, em áudios e pesquisa da literatura pertinente. Constatou-se a existência de empreendimentos de piscicultura continental em sua quase totalidade. Contudo, essas atividades apresentam problemas relacionados à disponibilidade de insumos, produção, escoamento e beneficiamento, além de entraves no ambiente institucional. A cadeia produtiva da piscicultura no Oeste paraense demanda de investimentos em insumos e produção da cadeia de forma profissional; que podem ser públicos ou privados, assim como uma maior integração e cooperação entre seus pares e ambientes.

PALAVRAS-CHAVE: Aquicultura, Produtores e instituiç̃es, Santarém e Mojuí dos Campos.

\section{STRENGTHS AND FRAGILITIES OF THE PISCICULAR SECTOR IN SANTARÉM AND MOJUÍ DOS CAMPOS, PA -BRAZIL}

ABSTRACT: This paper aims to present the strengths and weaknesses of the producers and institutions that work in the aquaculture sector of Santarém and Mojuí dos Campos, PA - Brazil. As well, characterize these aquaculture producers; present the objectives and mission of institutions working in the aquaculture sector; and quantify the strengths and weaknesses of local producers and institutions. Qualitative interviews were carried out with the application of forms and semi-structured guides, with 44 fish farmers and 08 representatives of associations, cooperatives, development agencies and bodies responsible for aquaculture. Photographic records were also made, in 
audios and relevant literature research. It was verified the existence of ventures of continental pisciculture in its almost totality. However, these activities present problems related to the availability of inputs, production, disposal and processing, as well as obstacles in the institutional environment. The productive chain of fish farming in the West of Para requires investment in inputs and production of the chain in a professional way; which can be public or private, as well as greater integration and cooperation between peers and environments.

KEYWORDS: Aquaculture, Producers and Institutions, Santarém and Mojuí dos Campos.

\section{FORTALEZAS Y FRAGILIDADES DEL SECTOR PISCÍCOLA EN SANTARÉM Y MOJUÍ DE LOS CAMPOS, PA -BRASIL}

RESUMEN: Este trabajo tiene como objetivo presentar las fortalezas y fragilidades de los productores e instituciones que actúan en el sector acuícola de Santarém y Mojuí de los Campos, PA - Brasil. Así como, caracterizar a esos productores acuícolas; presentar los objetivos y misión de las instituciones que actúan en el sector acuícola; y cuantificar las fortalezas y fragilidades de los productores e instituciones locales. Se realizaron entrevistas cualitativas con aplicación de formularios y de itinerarios semiestructurados, junto a 44 piscicultores y 08 representantes de las asociaciones, cooperativas, agencias de fomento y organismos responsables por la actividad acuícola. También se realizaron registros fotográficos, en audios e investigación de la literatura pertinente. Se constató la existencia de emprendimientos de piscicultura continental en su casi totalidad. Sin embargo, estas actividades presentan problemas relacionados con la disponibilidad de insumos, producción, desagüe y beneficiamiento, además de obstáculos en el ambiente institucional. La cadena productiva de la piscicultura en el oeste paraense demanda de inversiones en insumos y producción de la cadena de forma profesional; que pueden ser públicos o privados, así como una mayor integración y cooperación entre sus pares y ambientes.

PALABRAS CLAVE: Acuicultura, Productores e instituciones, Santarém y Mojuí de los Campos.

\section{INTRODUÇÃO}

A Pesca e a Aquicultura são importantes atividades para a geração de alimentos, emprego e renda para centenas de milhões de pessoas que atuam direta ou indiretamente na 
cadeia de produção e distribuição do pescado em todo o mundo (MERONA; BITTENCOURT, 1988; CERDEIRA et al., 1997; BATISTA et al., 1998; FAO, 2016).

Nesse cenário a produção mundial de pescado cresce anualmente estimulando o aumento do consumo per capta, que alcançou um novo máximo histórico de 20kg/pessoa/ano em 2014, graças a um intenso crescimento da aquicultura, que na atualidade proporciona a metade de todo o pescado destinado ao consumo humano, fortalecendo o papel do pescado como um dos produtos alimentícios mais comercializados ao nível mundial, com destaque para as exportações procedentes de países em desenvolvimento (FAO, 2016).

A aquicultura é a atividade que mais cresce no Brasil e no Mundo, e, portanto, as oportunidades de mercado (SEBRAE, 2015). No Brasil, a criação de peixes em cativeiro é uma atividade em expansão que apresentou crescimento de 10,0\% em 2016 e um faturamento estimado em $\mathrm{R} \$ 4,5$ bilhões (IBGE, 2016), porém, apesar desses indicadores, existe uma heterogeneidade nas cadeias de produção entre os estados (BRABO, 2014; BRABO et al., 2014b).

Embora a indústria da aquícola no Brasil venha crescendo a uma taxa superior a $15 \%$ a.a., o potencial para a expansão dessa atividade ainda é pouco aproveitado devido à falta de uma política efetiva para organizar e promover o desenvolvimento dessa atividade como importante produtora de alimentos. Assim como para a região de estudo, o conhecimento da real potencialidade da aquicultura no Brasil se deve à falta de diagnóstico, de ciência e tecnologia, da dispersão territorial e a falta de uma integração entre os setores que compõem os diversos elos de sua cadeia produtiva, o que deixa clara a necessidade de produção de conhecimento para esse setor produtivo (EMBRAPA, 2002).

Em comparação a outros estados que compõem o território brasileiro, a aquicultura no Pará é pouco expressiva em escala comercial, apesar de estar presente em todos os seus municípios 
e contribuir para geração de ocupação de mão-de-obra, geração de renda e a produção de alimento (LEE; SARPEDONTI, 2008; BRABO et al., 2016b). É uma atividade que abrange à piscicultura continental, a carcinicultura marinha e a ostreicultura (BARBO, 2014a), onde a piscicultura, cultivo de peixes em ambiente confinado, tem despertado grande interesse por parte de pequenos e médios empresários em todo o país, por se tratar de um empreendimento que tem uma alta taxa de aceitação no seu produto final (GAMA, 2008).

Na Região Oeste do Pará, a produção piscícola em Santarém, Mojuí dos Campos e Belterra foi estimada em 150 toneladas, segundo a Secretaria de Estado do Desenvolvimento Agropecuário e da Pesca - SEDAP, derivada de 39 criadores cadastrados pela Secretaria Municipal de Agricultura e Pesca - SEMAP. Nesse cenário, Santarém é um importante mercado consumidor, onde são desembarcadas 1.200 toneladas/ano de pescado, das quais 25,0\% são importadas de criadouros de Rondônia e Mato Grosso, segundo dados da Secretaria de Estado da Fazenda (OESTADONET, 2017).

O desenvolvimento do setor aquícola na região de Santarém e Mojuí dos Campos demanda, portanto, o entendimento das diferentes visões que possuem os produtores e as instituições que atuam no setor. Nessa ótica, o presente estudo apresenta uma caracterização dos produtores regionais e instituições que atuam no setor, elencando os pontos fortes e as fragilidades que enfrentam, de forma a viabilizar informações que possam subsidiar políticas públicas que busquem solucionar os problemas e aproveitar as potencialidades locais.

\section{MATERIAL E MÉTODOS}

O estudo foi realizado no polígono que contempla os municípios de Santarém e Mojuí dos Campos (integrantes a mesorregião do Baixo Amazonas), nas regiões: do Planalto (Mojuí dos Campos-zona metropolitana de Santarém) onde está 
um ecossistema anteriormente de mata secundária e plantações de monoculturas de grãos; região do Eixo Forte (estrada PA-457 até Alter-dochão) onde ocorre áreas de "savanas amazônicas" e predominância de corpos d'água; região periurbana (Maicá, Pérola do Maicá, Santarenzinho) com ecossistemas de áreas alagadas por cursos d'água, notadamente igarapés que abastecem a rede de água; a região do Tapará (com área de assentamentos do
INCRA/SPU) com ecossistema de várzea e águas brancas do rio Amazonas; a região do Arapiuns, num ecossistema de rios mais antigos e com influência de poucos sedimentos e por último, a região do Curuá-Una, onde tem-se um ecossistema de rios de influência de ácidos húmicos e fúlvicos, ricos em sedimentos orgânicos em decomposição, também dado a presença da UHC 'a montante.

Figura 1. Mapa situacional de Santarém e regiões do polígono estudado.

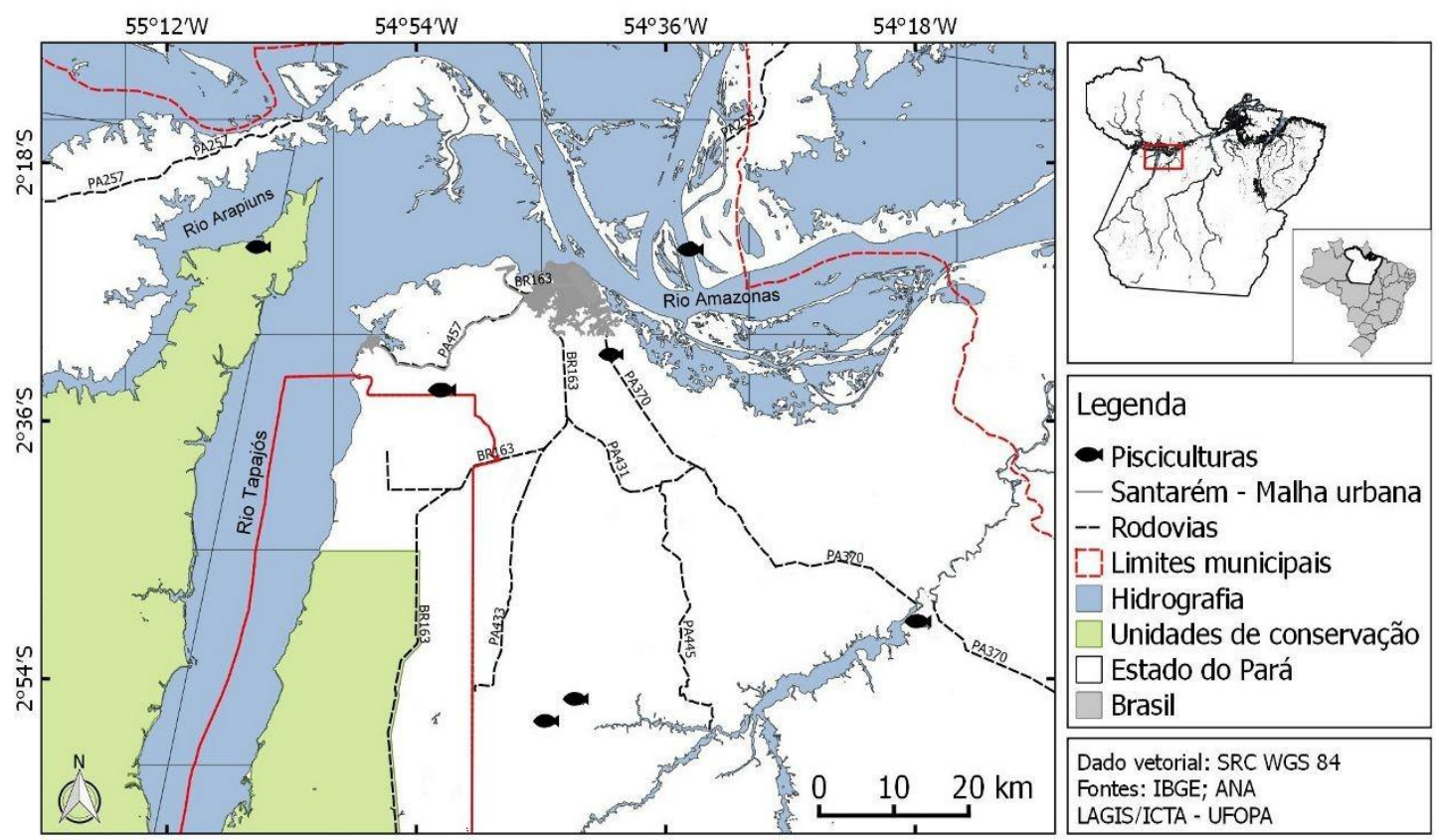

Fonte: Leal, J. out/2016. 
A coleta de dados foi realizada de dez/2015 a nov/2016 através da aplicação de formulários e roteiros semiestruturados (BARDIN, 2010) junto aos produtores, representantes das associações, cooperativas, agências de fomento e órgãos responsáveis pela atividade aquícola. Além de registro fotográfico e em áudio.

Para os produtores foram coletadas informações referentes as suas características socioeconômicas (idade, escolaridade, renda familiar e renda da aquicultura) e os pontos fortes e as fragilidades que enfrentam na atividade: motivação da inserção no setor, formas de implantação do projeto, dados produtivos e licenciamento da atividade, conhecimento da atividade, tempo na atividade, cursos no âmbito da atividade que exercem e a visão que têm do setor. Das Instituições, os objetivos institucionais, missão, atividades desenvolvidas e os pontos fortes e as fragilidades no quesito operacionalidade e a visão que têm do setor.

Para esse fim, a pesquisa foi aprovada pelo Comitê de Ética e Pesquisa da
Universidade do Estado do Pará- UEPA (CAAE 50019915.8.0000.5168) e todos os entrevistados, antes do início das entrevistas com Roteiro préestabelecido, foram esclarecidos e assinaram um Termo de Consentimento Livre e Esclarecido - TCLE. Informações complementares foram obtidas de relatórios técnicos e publicações ligadas ao setor aquícola.

Os dados formam tabulados em planilhas do programa Microsoft Office Excel, versão 2013, analisados mediante o emprego de ferramentas da estatística descritiva (ZAR, 1999) e apresentados no formato adaptado da Matriz FOFA (Fortalezas, Oportunidades, Fraquezas e Ameaças) (GOMIDE et al., 2015), onde os dados de campo se traduzem em ferramentas para o planejamento e gestão com base na visualização sistematizada dos pontos fortes (Fortalezas e Oportunidades) e das fragilidades (Fraquezas e Ameaças) de um coletivo social, permitindo a avaliação de sua estrutura, desempenhos e/ou contextos. 


\section{RESULTADOS E DISCUSSÃO}

Foram entrevistados 44 produtores (5 do município de Mojuí dos Campos e 39 de Santarém) e 8 representantes de instituições ligadas ao setor aquícola: Empresa de Assistência Técnica e Extensão Rural do Estado do Pará - EMATER-PA, Secretaria de Estado do Desenvolvimento Agropecuário e da Pesca - SEDAP, Secretaria Municipal de Meio Ambiente de Santarém - SEMMA, Cooperativa de Piscicultores do Tapajós - COOPATA, Sistema de Crédito Cooperativo - SICREDI, Associação dos Piscicultores e Agroextrativistas da Comunidade de Anã/Arapiuns - APAA, Banco do Brasil e Frigorífico Peixão.
No aspecto socioeconômico dos produtores foi relatado que o primeiro produtor iniciou suas atividades em $1995 \mathrm{e}$ que mais da metade nos últimos 7 anos. Possuem de 27 a 75 anos e média de 51,16 $\pm 10,48$ anos, predominantemente do gênero masculino $(79,5 \%)$ e nível de escolaridade entre o ensino fundamental (45,5\%), médio (25,0\%) e superior (29,5\%). Aproximadamente $77,8 \%$ estão filiados a entidades representativas (Associação, Cooperativa ou Sindicato), com faixa de renda familiar predominante de $1 \vdash 3$ salários mínimos/mês (34,8\%), onde a faixa derivada da aquicultura é inferior a um salário mínimo por mês (65,5\%) (Figura 2).

Figura 2. Renda familiar e derivada da aquicultura dos produtores entrevistados.

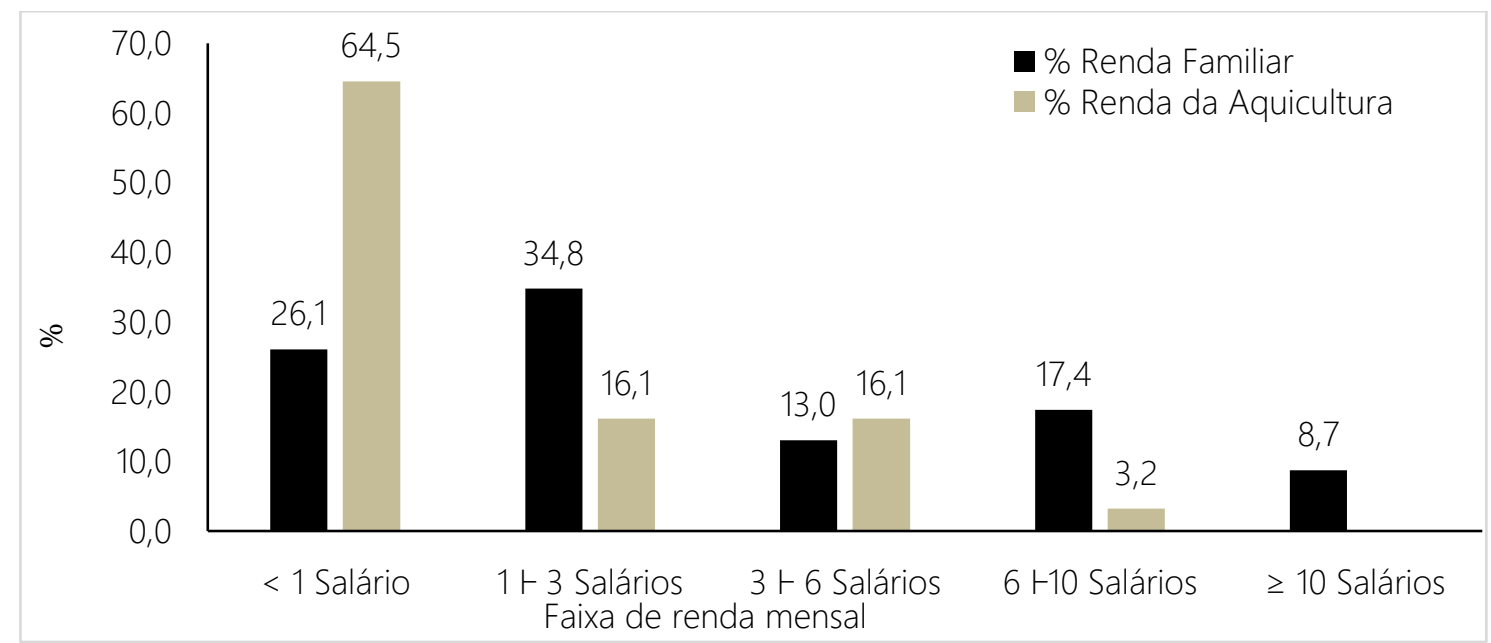

Fonte: Faria, 2017. 
Na esfera instituições, a EMATER é um órgão oficial de Assistência Técnica e Extensão Rural - ATER do estado do Pará, que objetiva prestar serviços especializados nas áreas de Ciências Agrárias e Humanas, difundindo conhecimentos e informações tecnológicas no meio rural, sob princípios norteadores de equidade, eficiência e sustentabilidade. Sua sede em Santarém conta com um quadro de 42 funcionários, sendo 39 do quadro funcional da Empresa e 03 cedidos pela Secretaria Municipal de Agricultura e Incentivo à Produção Familiar - SEMAP, além de dispor de um orçamento mensal no valor de $\mathrm{R} \$$ 8.000,00 conforme convênio celebrado com Prefeitura Municipal de Santarém, via - SEMAP, para execução das atividades de campo, sendo o salário dos funcionários pago pelo Governo do Estado do Pará.

Atua na área de Assistência Técnica e Extensão Rural - ATER junto a aproximadamente $\quad 5.000$ famílias distribuídas no planalto santareno nos eixos das principais estradas Santarém Curuá-Una, Santarém Cuiabá e vicinais que ligam a Zona Rural, bem como nas regiões do Ituqui, Santarém-Miri e ainda na região dos rios Aritapera, Ituqui, Tapará e Urucurituba. Auxiliam no acompanhamento técnico para o acesso ao Crédito Rural, com maior ênfase no Programa Nacional de Fortalecimento da Agricultura Familiar - PRONAF através dos Bancos da Amazônia e Banco do Brasil, além da emissão de Declaração de Aptidão ao Pronaf - DAP e Cadastro Ambiental Rural - CAR. Na área da aquicultura, a partir de 1996, iniciaram as atividades voltadas para atender os pequenos e médios piscicultores do município de Santarém, visando estimular a geração de ocupação e renda e a subsistência familiar, mediante ações de capacitação e palestras sobre a criação de peixes em tanques-rede, tanques escavados, beneficiamento do pescado, cooperativismo e associativismo para os mesmos, assistindo atualmente a 45 piscicultores cadastrados na instituição em parceria com a SEDAP, através da COOPATA.

A Secretaria de Estado do Desenvolvimento Agropecuário e da Pesca - SEDAP é o resultado da fusão das Secretarias Estaduais de Agricultura e de Pesca. É uma instituição estadual que têm 
a finalidade de promover o desenvolvimento sustentável e o fortalecimento das atividades agrícolas, pecuárias, pesqueiras e aquícolas no Pará, em todas as suas modalidades, possibilitando 0 incremento dos benefícios sociais e econômicos desses setores, visando o bem-estar da sociedade. No setor aquícola atua no fomento e estímulo da atividade mediante a aplicação de cursos, palestras, oficinas e visita as unidades produtivas. Dispõe de uma unidade de produção de alevinos denominada de Estação de Aquicultura Santa Rosa, que possui outorga de água, e uma infraestrutura com aproximadamente 2,86ha de lâmina d’água e 5,18ha de área construída de viveiros (18 viveiros para pesquisa dentre os 35 viveiros de recria e engorda) e laboratório com capacidade para uma produção anual estimada de 10.000.000 de pós-larvas e 2.000.000 alevinos de tambaqui (Colossoma macropomum), pirapitinga (Piaractus brachypomus), curimatã (Prochilodus nigricans), matrinchã (Brycon amazonicus) e pirarucu (Arapaima gigas).
A Secretaria Municipal de Meio Ambiente de Santarém - SEMMA é uma instituição do município que desenvolve políticas ambientais buscando a sensibilização e o comprometimento da população, no uso sustentável dos recursos e serviços ambientais no município de Santarém. Desenvolve as políticas socioambientais do município de Santarém com ampla participação da sociedade organizada e da população em geral para garantia da qualidade de vida. Dispõe de um orçamento anual de $R \$$ 2.480.150,00. Atua na regularização e controle ambiental dos empreendimentos aquícolas cadastrados e devidamente licenciados, em cumprimento a Legislação Ambiental vigente no País, buscando conservar as potencialidades Amazônicas no território de Santarém, visando a preservação de determinados ecossistemas e a cultura local, de forma integrada.

A Cooperativa de Piscicultores do Tapajós - COOPATA, tem como objetivo a integração de produtores, técnicos e estudantes no intuito de produzir alimentos e tecnologia, para colaborar no atendimento da crescente demanda por 
alimentos de origem aquícola. Atua na formatação de parcerias juntos as instituições de ensino, pesquisa e extensão para capacitar seus cooperados com cursos voltados ao cooperativismo e a produção de peixes comerciais de grande porte. Possui 29 cooperados e atualmente conta com o apoio de um Engenheiro Agrícola na elaboração de projeto de criação de peixes em tanquesrede e sua legalização, contando com recursos do Sistema de Crédito Cooperativo - SICREDI, pleiteando assinatura de um acordo de cooperação com a UFOPA e a UHE Curuá-Una, onde o sistema de criação de peixes em tanques-rede poderá ser implantado.

Entre seus cooperados, a maioria do cultivo é extensivo (86,5\%), uma vez que é desenvolvido por produtores que não dispõe de acesso a financiamentos, por ocuparem áreas de assentamento, aproveitando assim, áreas alagadas em média de 0,72 \pm 0,12ha, para piscicultura, o restante utiliza o sistema semi-intensivo.

Dentre as instituições de financiamento para cooperados ou afins, destacamos aqui o Sistema de Crédito Cooperativo SICREDI, que é uma instituição financeira cooperativa que valoriza a vocação econômica das regiões, cria oportunidades para o desenvolvimento sustentável de negócios e promove o desenvolvimento dos seus associados. Conta com um orçamento aproximado de R\$ 312.000.000,00 e suas ações visam atender as demandas dos associados e agregar renda às suas atividades, ofertando soluções financeiras para melhoria da qualidade de vida da população. Dispõe de 30 assessores que auxiliaram na demanda, acompanhamento técnico do plantel com vistoria "in loco" e na documentação para o financiamento. Em Santarém existe a quase dois anos e está analisando a proposta de um projeto-piloto de 4,0ha da COOPATA na ordem R\$500.000,00 (investimento de crédito).

Associação de Piscicultores de Anã/Arapiuns - APAA tem como objetivo o fortalecimento da produção agrícola na comunidade de Anã e entorno (região de Arapiuns), mediante ações de capacitação dos seus associados num trabalho educativo voltado ao fortalecimento comunitário e o cultivo de peixes (biometria do plantel de peixes, limpeza 
de tanques, alimentação dos peixes e monitoramento da qualidade de água), além da formulação e fabricação de ração, com o apoio do Serviço Nacional de Aprendizagem Rural - SENAR / Comissão Executiva de Planejamento da Lavoura Cacaueira - CEPLAC, com vista no melhoramento da atividade e geração de renda. A associação acessou investimento da ordem $\mathrm{R} \$ 60.000,00$ para aplicar no projeto de criação de peixes em tanques-redes, que obteve boa rentabilidade e apesar do custo, a produção tem mercado garantido. Na continuidade dos ciclos de produção, além da alimentação balanceada fornecida ao plantel de peixes com o uso de ração comercial, desenvolveram uma ração com base de produtos regionais para a alimentação dos peixes que vem mostrando bons resultados.

Banco do Brasil tem como meta ser o banco mais confiável e relevante para a vida dos clientes, funcionários e para o desenvolvimento do Brasil. A missão do Banco do Brasil é ser um banco rentável e competitivo, atuando com espírito público em cada uma de suas ações, junto a clientes, acionistas e toda sociedade. Para tanto, disponibiliza ao setor produtivo linhas de crédito ligadas ao PRONAF e busca participar dos fóruns de discussão voltados ao fortalecimento e crescimento do setor aquícola regional.

O Frigorífero Peixão é uma Indústria de Beneficiamento de Pescado - IBP criada com a finalidade de comercializar e industrializar pescado. Iniciou suas atividades em Santarém há aproximadamente 25 anos. Possui Sistema de Inspeção Federal - SIF implantado para atender as normas sanitárias exigidas pela legislação e mantêm seus funcionários e técnicos capacitados para a manipulação, armazenagem e beneficiamento de pescado, manipulação sanitária de alimentos e de gelo. Atua na compra e venda de peixes com relação voltada na sua maior parte com pescadores artesanais, pois o pescado oriundo da piscicultura não oferece mercado (isso na visão do entrevistado), visto que o público quer partes específicas do pescado vindo da piscicultura, o que para a gerência local, não compensa adquirir dada as perdas que ocorrerão. 
Os pontos fortes e fragilidades pontuadas por produtores e representantes de instituições ligadas ao setor aquícola local são em alguns pontos análogos e outros antagônicos, permitindo uma visão ampla e representativa.

A realidade ora pesquisada mostra pontos fortes (Fortalezas e Oportunidades) que o seguimento de produção de peixes em cativeiro possui nos municípios de Santarém e Mojuí dos Campos, com um mercado crescente e um enorme potencial hídrico, assim como mostra as fragilidades (Fraquezas e Ameaças), devido à baixa capacidade de atender a demanda local e competir com a produção de outros estados pois, segundo Zacardi et al. (2017) a produção local é incipiente devido à dificuldade do acesso burocrático aos incentivos governamentais e a não difusão de tecnologia adequada.

Para o universo amostral dos produtores as potencialidades se relacionam:

- A propriedade da terra: a maioria dos produtores declara ser proprietário da terra $(79,5 \%)$ ou detêm a posse social
(2,6\%), o que pode facilitar o processo de licenciamento, além de residirem na propriedade $(66,0 \%)$, o que pode facilitar o processo de monitoramento do cultivo. - A comercialização da produção: os produtores destacaram que ao fim do ciclo produtivo não têm problema para vender a produção $(72,7 \%)$ e aproveitam para comercializá-la principalmente no período de maior demanda, que ocorre na Semana Santa, quando a prefeitura e órgãos reguladores do setor dão apoio nessa comercialização.

- Oferta de alevinos: atualmente a oferta de alevinos por parte da SEDAP para os produtores da região é superior ao estimada por Arnaud (2012) para as mesorregiões metropolitanas de Belém e nordeste paraense.

As fragilidades se relacionam:

- A forma de inserção na atividade: somente $18,4 \%$ iniciaram a atividades por conhecer ou entender sua viabilidade econômica, os demais iniciaram a atividade por lazer, paixão pela atividade, incentivo de amigos e parentes, o acaso em adquirir propriedade com cultivo instalado e o cultivo apenas com vista a subsistência familiar. $\bigcirc$ fato da 
predominância da forma "amadora", ou sem profissionalismo contribui negativamente para a viabilidade da piscicultura;

- A falta de planejamento: não há planejamento do sistema de cultivo, sendo comum a modificação e ajustes não planejados no sistema original (70,5\%), uma vez que apenas 25,0\% dos produtores possui assistência técnica privada, os demais não possuem nenhuma assistência técnica (43,2\%) ou dependem da assistência esporádica dos órgãos de assistência técnica institucional (31,8\%). Fator que influencia negativamente no monitoramento do sistema de criação, que ocorrem mensalmente para somente $6,8 \%$ dos produtores, 4,5\% semestralmente e os demais de 1 a 4 vezes ao ano;

- A limitação de acesso ao crédito: os produtores destacam que têm dificuldades de acessar a linhas de crédito para investir na atividade (87,2\%), e entre os que tiveram acesso ao crédito, não necessariamente o obtiveram direcionado para a atividade, assim, o próprio produtor foi quem construiu o ambiente de cultivo com recurso próprios (72,7\%) e arcou com o custeio do ciclo produtivo;

- O custo elevado dos insumos: no contexto produtivo os principais problemas se relacionam ao elevado preço da ração comercial $(45,5 \%)$ o que estimula o uso de alimentação alternativa e inadequada;

- Falta de incentivos do governo: os produtores relataram que não têm apoio do governo municipal, estadual ou federal na viabilização de assistência técnica, maquinário para apoiar a construção dos viveiros de cultivo e não percebem a atuação na busca de linhas de crédito para investimento e custeio;

- Os furtos: os produtores destacaram que estão cada vez mais frequentes os furtos dos peixes nas propriedades;

- A falta de controle da produção: cerca de $63,6 \%$ não fazem registros de dados produtivos, o que dificulta análises técnicas para a determinação dos índices de produção, produtividade e retorno econômico;

- Desorganização dos produtores: a falta de organização dos produtores regionais resulta em um custeio mais oneroso da atividade, pois o principal insumo na 
atividade, a ração, é adquirida em pequenas quantidades de forma individualizada, limitando a compra em escala que viabilizem melhores preços ao produtor, o que afeta diretamente os custos de produção;

- O custo elevado para custeio e investimento: a região tem carência de empresas que atuem na fabricação e comercialização de tanques-rede e construção de viveiros, o que encarece os investimentos para o ingresso na atividade.

Entre os pontos fortes das instituições ligadas a aquicultura na área de estudo foram relatadas:

A integração institucional multidisciplinar: nos últimos cinco anos vêm ocorrendo uma série de reuniões e debates entre instituições federais, estaduais, municipais, universidades, empresas, produtores, sociedade civil organizada e organizações não governamentais - ONG's, de forma multidisciplinar, para a elaboração de uma diagnose da atividade piscícola e a elaboração de um planejamento flexível e exequível voltado para a solução dos problemas do setor aquícola local, contando com o acompanhamento de uma equipe de profissionais de várias áreas para dar o suporte necessário para a mitigação de outros problemas que possam vir a surgir no decorrer da execução do planejamento. Dois exemplos a destacar são. $\bigcirc$ primeiro remete ao Grupo de Gestão Integrada para o Plano Desenvolvimento Regional Sustentável, promovido pela anterior gestão da prefeitura de Santarém, que estimulou a discussão de representantes das diferentes cadeias de produção regional, entre elas a da aquicultura e ainda em execução, a elaboração de um Plano de Desenvolvimento Sustentável da Pesca do Baixo Amazonas - PDPBA, que está promovendo uma diagnose da atividade pesqueira e aquícola na região do baixo Amazonas desde dez/2016 até junho/2017, com base em reuniões para a Elaboração do PDPBA. Em seu grupo de trabalho do subcomponente Piscicultura vem promovendo reuniões para elencar propostas para identificar e mitigar as possíveis problemáticas e dificuldades da piscicultura regional, incentivar a produção de peixes em cativeiro na região do Baixo Amazonas, subsidiando 
aos pescadores e ribeirinhos mais uma alternativa econômica e de produção de alimentos e gerar e implementar ações no setor público para desenvolvimento da atividade;

- Incentivos do governo: no âmbito estadual existem políticas de incentivos ao desenvolvimento da atividade pesqueira e piscícola, dentre eles o Programa Estadual de Apoio Agropecuário e Pesca onde a EMATER-PA é responsável pelo Projeto de "Apoio a Pescadores Artesanais e Aquicultores com Assistência Técnica e Extensão Pesqueira e Aquícola". Para esse apoio os escritórios da EMATER dispõem de um quadro de funcionários multidisciplinar que ampliam as possibilidades para atender diferentes setores produtivos: Sociólogos, Pedagogos, Técnicos em Agropecuária, Técnicos Agrícolas, Técnicos Sociais, Engenheiros Agrônomos, Engenheiros Florestais, Engenheiros de Alimentos, Engenheiros Ambientais, Veterinários e Engenheiros de Pesca;

- Cooperação interinstitucional: estão formatados ou em processo de formatação Termos de Reciprocidade ou Cooperação Técnica entre a EMATER-PA e outros atores, INCRA, ICMbio, MAPA, ADEPARA, SEDAP, Prefeitura de Santarém, Universidades e Colônia de Pescadores voltados ao favorecimento e execução de serviços que podem contribuir para o desenvolvimento e a mitigação dos problemas hoje encontrados na cadeia produtiva da pesca e piscicultura.

Entre as fragilidades institucionais foram listadas:

- As dificuldades operacionais: a limitação de recursos para cobrir os custos das ações de campo e o quadro técnico limitado para cobrir grandes áreas e muitos produtores resultam no baixo índice de desenvolvimento da atividade piscícola de subsistência ou comercial devido à falta de um acompanhamento técnico multidisciplinar que garantam uma visão holística de toda a cadeia, com a finalidade de identificar e mitigar a problemática que envolve a atividade;

- A limitação do conhecimento local: representantes institucionais destacaram que existe uma carência de pesquisas apropriadas (aspectos produtivos do setor, melhoramento genético e estudos nutricionais das espécies de peixes 
regionais hoje cultivadas, laboratórios especializados em alevinagem, medidas de profilaxia e controle sanitário) para o desenvolvimento da piscicultura no município de Santarém e mesmo no Estado do Pará e afirmam que o conhecimento hoje disseminados derivam de pesquisas informais realizadas por piscicultores e técnicos de instituições afins;

- A informalidade da atividade: a falta de licenciamento ambiental da atividade impede que as instituições dêem o apoio institucional na obtenção de financiamento via PRONAF, restringindo o acesso dos produtores a capital com juros baixos e a garantia de assistência técnica. Como resultado, atualmente no município de Santarém não há projetos com financiamento de crédito para piscicultores;

- Desorganização dos produtores: os produtores atuam de forma pulverizada, o que dificulta e onera o atendimento técnico por conta das demandas pontuais, bem como de ações de capacitação;

- Falta de logística: a falta de patrulha mecanizada (trator de esteira, pá mecânica, caçamba e retroescavadeira) vinculada às Prefeituras de Santarém e Mojuí dos Campos, para apoiar a reforma/adequações ou construção de ambientes de cultivo, principalmente para produtores com baixo poder aquisitivo inviabilizam o crescimento e o desenvolvimento do setor aquícola em função dos altos custos;

- Falta de empresas instaladas na região: a falta de empresas que fabriquem ração, estruturas de apoio ao cultivo de peixes como tanques-redes, redes de despesca, aparelhos para medição de parâmetros limnológicos, além de empresas que atuem na área de construção de viveiros encarece o custo de manutenção do plantel e os investimentos para o ingresso na atividade.

Os resultados mostram a existência de pontos análogos e antagônicos entre a visão dos produtores e representantes institucionais, porém, mostra que aparentemente existem mais fragilidade que potencialidade para o desenvolvimento do setor aquícola local. Na ótica dos pontos fortes, a oferta de alevinos para a Região Oeste superior a outras regiões do estado do Pará mostra o esforço institucional para atender o 
crescente interesse pela e crescente demanda, como resultado do potencial de crescimento da atividade (GAMA, 2008; LEE; SARPEDONTI, 2008; BARBO, 2014a; BARBO et al., 2016a).

Quanto as fragilidades, a falta de profissionalismo como resultado da forma de inserção do produtor na atividade aquícola, resulta em uma produção amadora (PIZAIA et al., 2008) e sem perspectivas de crescimento, prejudicando o próprio produtos que acaba se desestimulando com a atividade.

Devido a carência de empresas na região, os preços das rações para peixe ainda são muito altos apesar dos avanços tecnológicos em seu processo produtivo das últimas três décadas e representam de $50 \%$ a $80 \%$ do custo de produção das pisciculturas comerciais (BRABO et al., 2016b). Essa realidade da aquicultura na área de estudo resulta em pouca competitiva, realidade não diferente da já relata por BRABO (2014a) e BRABO et al. (2014b) para alguns municípios do Estado do Pará, apesar das condições naturais privilegiadas para o desenvolvimento das mais diversas modalidades aquícolas (BRABO et al., 2016a).
As discussões setoriais que contam com a participação de produtores, instituições públicas, privadas e ONG's observadas na área de estudo são importantes fóruns para elencar as potencialidades, fortalezas e projetar ações coordenadas e direcionadas ao desenvolvimento e sustentabilidade do setor aquícola, se constituindo ferramentas importantes e frequentemente utilizadas, como o observado no estudo de Leal e colaboradores (2006).

Entretanto, o cultivo de peixes e outros organismos aquáticos na região de estudo conta com um grande potencial para crescimento, seja no que se relaciona ao suprimento da oferta de tambaqui durante o período de proibição da pesca (DEFESO) e entressafra na região, como também para suprir a crescente demanda do mercado local, que hoje é abastecido por produtores de outros estados, principalmente dos estados do Mato Grosso e Rondônia.

\section{CONCLUSÃO}

A produção aquícola/piscícola na região de Santarém e Mojuí dos Campos 
apesar de seu grande potencial regional (produção de alevinos de espécies nativas, recursos hídricos e temperatura) e crescente interesse pela atividade, enfrenta dificuldades típicas de regiões em desenvolvimento, tais como: insuficiência em insumos básicos, falta de assistência técnica, limitação de acesso ao crédito e baixa competitividade. O que requer o fortalecimento do setor para solucionar as diferentes fragilidades apresentadas por produtores e as instituições que atuam no setor e fazer com que a piscicultura possa vir a contribuir decisivamente com a segurança alimentar, ocupação de mão-de-obra e geração de renda para os atores envolvidos na cadeia de produção e comercialização.

Para tanto se faz necessário investir em insumos e produção da cadeia de forma profissional, além de uma maior atuação das organizações sociais, inclusive politicamente, defendendo os interesses da atividade em conselhos e nas três esferas de governo, uma vez que o Pará já é um grande produtor de pescado oriundo do extrativismo e tem potencial para fazê-lo também pela aquicultura, em especial pela piscicultura continental.

\section{AGRADECIMENTOS}

À Universidade Federal do Oeste do Pará (UFOPA); à FAPESPA, pela cessão de bolsa de doutorado, para a primeira autora do artigo.

\section{REFERÊNCIAS}

ARNAUD, J. S. Situação da piscicultura nas regiões do Guamá e Capim, Pará, Amazônia brasileira, 2012. $60 \mathrm{f}$. Dissertação (Mestrado em Aquicultura e Recursos Aquáticos Tropicais) Universidade Federal Rural da Amazônia, Coroado, 2012.

BARDIN, L. Análise de conteúdo. Trad. Luis Antero Reto e Augusto Pinheiro. Lisboa: Edições 70, 2010. 281 p.

BATISTA, V.S.; INHAMUNS, C.E.; FREITAS, C.E.; FREIRE-BRASIL, D. Characterization of the fishery in river communities in the low-Solimões/high-Amazon region. Fisheries Management and Ecology, 5, 1998. 419-435 p.

BRABO, M. F.; DIAS, B.C.B.; SANTOS, L.D.; FERREIRA, L.A.; VERAS, G.C.; CHAVES, R.A. Competitividade da cadeia produtiva da piscicultura no nordeste paraense sob a perspectiva dos extensionistas rurais. Informações Econômicas, São Paulo, v. 44, n. 5, p. 1-13, set./out. 2014a.BRABO, M. F; PEREIRA, L. F. S.; 
FERREIRA, L. A.; COSTA, J. W. P.; CAMPELO, D.A.V.; VERAS, G. C. A cadeia produtiva da aquicultura no nordeste paraense, Amazônia, Brasil. Informações Econômicas, SP, v. 46, n. 4, jul./ago. 2016a.

BRABO, M.F.; PEREIRA, L.F.S.; SANTANA, J.V.M.; CAMPELO, D.A.V.; VERAS, G.C. (2016b). Cenário atual da produção de pescado no mundo, no Brasil e no Estado do Pará: ênfase na aquicultura. Acta of Fisheries and Aquatic Resources, v. 4, n. 2, p.50-58.

Piscicultura no estado do Pará: situação atual e perspectivas. Actapesca, Sergipe, v. 2, n. 1, p. 1-7, 2014 b.

CERDEIRA, R.G.P.; RUFFINO, M.L.; ISAAC, V.J. Consumo de pescado e outros alimentos nas comunidades ribeirinhas do Lago Grande de Monte Alegre. Acta Amazônica, v. 27, n. 3,1997. 213-227p.

EMBRAPA. A Embrapa e Aquicultura. Demandas e prioridades de pesquisa/editores técnicos: Júlio Ferraz de Queiroz; José Nestor de Paula Lourenço; Paulo Choji Kitamura. - Brasília: Embrapa Informação Tecnológica, 2002. 35 p.; (Texto para discussão; 11).

FAO. 2016. El estado mundial de la pesca y la acuicultura 2016: contribución a la seguridad alimentaria y la nutrición para todos. Roma. 224 pp.

GAMA, C.de S. A criação de tilápia no Estado do Amapá como fonte de risco ambiental. Acta Amazônica, Manaus, v.38, n. 3, 2008, 525-530 p.

GOMIDE, M.; SCHÜTZ, G.E.; CARVALHO, M.A.R.; CÂMARA, V.M. 2015. Fortalezas, Oportunidades, Fraquezas e Ameaças
(Matriz FOFA) de uma Comunidade Ribeirinha Sul-Amazônica na perspectiva da Análise de Redes Sociais: aportes para a Atenção Básica à Saúde. Caderno de Saúde Coletiva, 2015, Rio de Janeiro, v. 23, n.3, p. 222-230.

KUBITZA, F. Panorama da aquicultura: aquicultura no Brasil: principais espécies, áreas de cultivo, rações, fatores limitantes e desafios. Panorama da Aquicultura, 2015, Rio de Janeiro, v. 25, n.150, 12 p.

LEAL, E.C.; MACEDO, R.L; MARQUES, L.C.T.; COSTA FILHO, P.P.; LOPES, C.A.C.; PEDROSO, L.M.; AGUIAR, O.; COUTO, L.C.; ROCHA NETO, O.G.; SANTOS, N.R.; DOURADO, R.S.A.; LOURENÇO, R.F.; MANGAS, D.; NASCIMENTO, N.A. Oficina de Identificação de Demandas e Prospecção de Tecnologias. Relatório Final do Projeto Ações Integradas para o Planejamento do Desenvolvimento Sustentável da Amazônia-PRODESAM. Belém-PA. ADA/OEA, 2006. 41 p.

LEE, J.; SARPEDONTI, V. Diagnóstico, tendência, potencial e política pública para o desenvolvimento da aquicultura. Belém: Secretaria de Estado de Pesca e Aquicultura, 2008. 109 p.

COSTA, A.L.S.; RODRIGUES, M.S.; RICCI, F. (2015). Caracterização da piscicultura na região de a Ariquemes, no Estado de Rondônia -RO. Campo-Território. Revista Geografia Agrária, v. 10, n. 20, p. 512-537.

MERONA, B.; BITTENCOURT, M.M. A pesca na Amazônia através do desembarque no mercado de Manaus: Resultados preliminares. Memoria de la Sociedad de las Ciências Naturales La Salle, 48(Supl. 2), 1988. 433-455 p. 
OESTADONET,

2017.

Peixe criado em cativeiro é mais da meta de do pescado consumido em Santarém. Ano XIV, Edição Digital nº 3035.

Santarém, Quarta, 12 Abril 2017.

Disponível

em

http://www.oestadonet.com.br/index.php ?option=com_k2\&view =item\&id=11691:p eixe-criado-em-cativeiro-e-mais-dametade-do-pescado-consumido-emsantarem\&ltemid=88> Acesso em: 12 abril, 2017.

OLIVEIRA, A.M.; SILVA, M.N.P.; ALMEIDAVAL, V.M.F.; VAL, A.L. Caracterização da atividade de piscicultura nas mesorregiões do estado do Amazonas, Amazônia Brasileira. Revista Colombiana Ciência Animal, v. 4, n. 1, p. 154-162, 2012.

PIZAIA. M.G; GABARDOCAMARA, M.G.; SANTANA, M.A.; ALVES, R. A piscicultura no brasil: um estudo sobre a produção e comercialização de "oreochromis niloticus". In: CONGRESSO DA SOCIEDADE BRASILEIRA DE ECONOMIA, ADMINISTRAÇÃO E SOCIOLOGIA RURAL -SOBER, 46., 2008,XLVI Rio Branco, Acre. Anais...: Rio Branco- AC: Agricultura Familiar e Ruralidade., 2008. 16p.

SEBRAE. Aquicultura no Brasil. Série Estudos Mercadológicos. Brasília: Sebrae Editora. 2015. 76p.

SOUZA, R.A.L. Piscicultura sustentável na Amazônia: perguntas e respostas. Belém. Universidade Federal Rural da Amazônia. Editora: UFRA. 2004. 107 p.

ZACARDI, D.M., LIMA, M.A.S., NASCIMENTO, M.M.; ZANETTI, C.R.M. Aquaculture's socioeconomic and productive caracterization developed in
Santarém, Pará. Acta of Fisheries and Aquatic Resources (no prelo), 2017.

ZAR, J.H. Biostatistical Analysis. Fourth Edition. Person Education.1999. 663 p. 